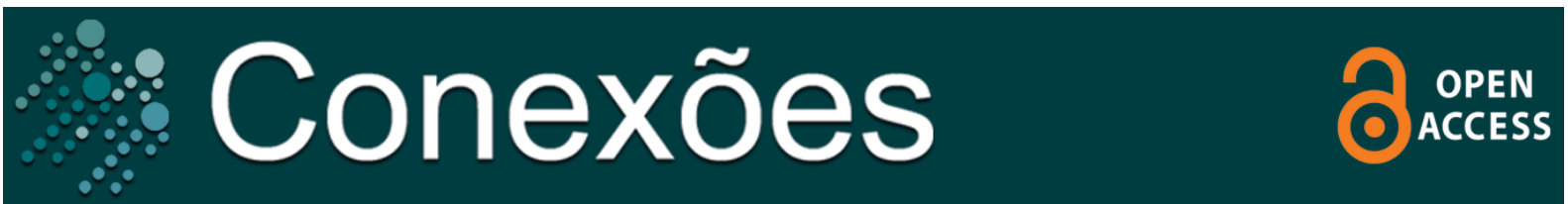

Editorial

\title{
O que mudou na Conexões?
}

\author{
What did change in the Conexões journal?
}

\section{¿Que cambió en el periódico Conexões?}

\author{
Edivaldo Góis Junior ${ }^{1}$ \\ Andréia Manzato Moralez ${ }^{1}$
}

Em meados do ano de 2016, a partir do convite da Direção da Faculdade de Educação Física da Unicamp, iniciamos a nova editoria da revista Conexões. A tarefa era hercúlea, pois encontramos um periódico sem nenhum membro no conselho editorial e sem indexações. Entretanto, havia uma tradição, já que de forma ininterrupta a revista era publicada assiduamente desde 1998. A revista tinha seus méritos, além da rigorosa periodicidade, era uma publicação que marcou os anos finais da década de 1990 com textos nas áreas de história e sociologia do esporte.

Naqueles anos, sob a direção do Prof. Ademir Gebara, a revista foi um importante veículo de divulgação nas pesquisas sobre as relações entre esporte, processo civilizatório e as contribuições de Norbert Elias. A partir de 2003, a revista torna-se institucionalmente vinculada à Faculdade de Educação Física, caminhando assim para uma maior pluralidade teórico-metodológica. Assim, ela buscou cada vez mais uma perspectiva interdisciplinar, sob a editoria do Prof. Gustavo Gutierrez.

Nestes anos, em termos estruturais, a Biblioteca "Prof. Asdrúbal Ferreira Batista" foi a principal fomentadora da revista, representada nas pessoas de primeiramente Dulce Inês Leocádio e atualmente Andréia Manzato Moralez.

\footnotetext{
1 Universidade Estadual de Campinas, Departamento de Educação Física e Humanidades, Campinas-SP, Brasil.

Correspondência:

Av. Érico Veríssimo, 701 Cidade Universitária "Zeferino

Vaz". Barão Geraldo - Campinas - SP. CEP: 13.083-851.

E-mail: gois@unicamp.br
} 
Portanto, se havia uma tradição, então era possível ampliar o impacto da Conexões nos cenários brasileiro e latino-americano. Para isso, foi necessário implementar uma série de estratégias coordenadas que permitiu nossa indexação na base de dados LILACS em 2021.

LILACS é a mais importante e abrangente base de dados de literatura científica na área de Ciências da Saúde no contexto da América Latina. O caminho para esta conquista residiu na efetivação de muitas mudanças, pois, afinal, o que mudou na Conexões?

Ao destacarmos algumas ações, uma bem perceptível foi na identidade visual da revista. Mudamos o layout, as capas, os logotipos, enfim houve uma mudança significativa nas questões estéticas, conforme o exemplo da capa de 2020 (Fig. 1).

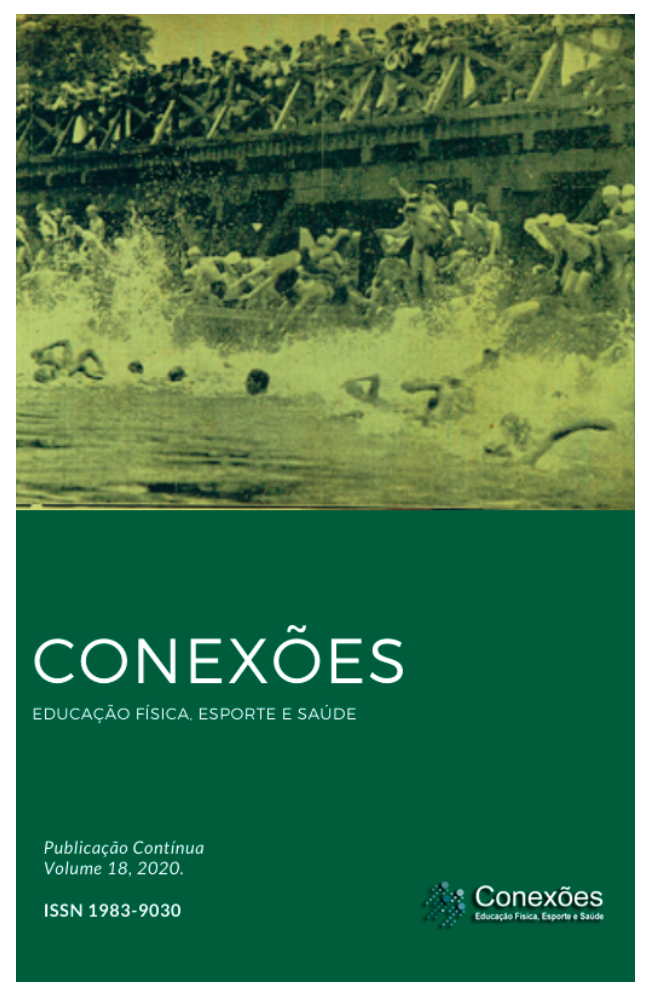

Figura 1 - Capa da revista Conexões com ilustração da Nona Travessia de São Paulo a Nado.

Fonte: Conexões (2020); A Gazeta (25 mar. 1935).

Mas a forma é apenas um elemento no trabalho editorial, seria preciso ainda formar uma rede de pesquisadores que sustenta os corpos de revisores, autores e principalmente de editores. No caso da Conexões, ampliamos o conselho editorial com maior diversidade de áreas como: ciências do esporte, atividade física e saúde, atividade física adaptada, e educação física escolar. Aumentamos o número de pesquisadores no conselho para 24, com acadêmicos do Brasil, França, Colômbia, Portugal, Estados Unidos, México, Uruguai e 
Espanha. Inserimos três pesquisadoras latino-americanas e fomentamos a participação das mulheres, que no momento são dez no conselho editorial.

Atualmente, a Revista Conexões possui 591 avaliadores cadastrados, sendo 291 avaliadores certificados (conferidos e atualizados). A equipe técnica da revista tem trabalhado arduamente no cadastro de avaliadores, a fim de garantir um amplo e qualitativo espectro de pareceristas na revista.

Dos 291 avaliadores já certificados, apenas 23\% são afiliados da Unicamp (FEF/FCA); $57 \%$ são da região Sudeste; $15 \%$ da região Sul; $7 \%$ da região Centro-Oeste; $9 \%$ da região Nordeste; $4 \%$ da região Norte; $8 \%$ de outros países.

Estes números permitem dizer que a endogenia não é mais um problema na revista. Além disso, a taxa de endogenia foi normativamente limitada pela organização de um regimento, aprovado em 2019 pela Congregação da Faculdade de Educação Física. O regimento da revista, em seu artigo 130., prevê que no máximo $20 \%$ dos artigos tenham autores e coautores oriundos da Faculdade de Educação Física da Unicamp.

Neste sentido, a revista cresceu e deixou de ser uma revista local. Outrossim, caminha para uma crescente internacionalização com a publicação de textos em inglês e espanhol e com autores estrangeiros. Todas as normas e diretrizes da revista são publicadas em inglês e espanhol. Em 2020 e 2021, foram publicados 18 (dezoito) artigos em espanhol, mas ainda precisamos avançar nestes resultados.

Em 2021, publicamos dois dossiês, "Os desafios da Educação Física em tempos de ataques à Educação", com a organização dos professores Marcos Garcia Neira (USP) e Mario Luiz Ferrari Nunes (UNICAMP); e "Educação Física, Linguagem e Corpo", com a organização dos professores Alberto Moreno-Doña (Universidad de Valparaíso, Chile) e Felipe Quintão de Almeida (UFES), além de artigos originais, de revisão e uma entrevista com o professor português Jorge Olímpio Bento.

Em 2022, teremos a publicação dos dossiês "40 anos do livro Universo do Futebol", com organização do professor argentino Alejo Levoratti (Universidad Nacional De La Plata, Argentina) e uma entrevista com o antropólogo Roberto DaMatta; e o dossiê "Ginástica para Todos", com a organização das professoras Laurita Schiavon (UNICAMP) e Eliana de Toledo (UNICAMP).

No período desta editoria, conquistamos a indexação em importantes bases de dados que ampliam a divulgação da revista, como o Lilacs, DOAJ, Latindex, Livre, REDIB - Red Iberoamericana de Innovación y Conocimiento Científico, ROAD - Directory of Open Access of Scholarly Resources, EBSCO, EZB - 
Electronic Journal Library, Index Copernicus International e Ulrich's Web. O trabalho realizado até aqui foi reconhecido e fomentou à editoria da Conexões o lugar de parecerista ad hoc na indexação de outras revistas da área no Lilacs e no Scielo.

No entanto, o trabalho de editoria é contínuo e outros desafios se impõem. No futuro próximo, almejamos as indexações no Redalyc e no Educ@, para depois investirmos no Scielo, Scopus e Web of Science. Aprendemos nestes anos que a construção da visibilidade da revista passa pela presença em bases de dados cada vez mais representativas. É como a subida de uma escada, degrau por degrau.

Foi preciso muito trabalho para que a revista se consolidasse no Portal de Periódicos Eletrônicos Científicos da Unicamp (PPEC), onde ocupamos a segunda posição em número de acessos (Fig. 2).

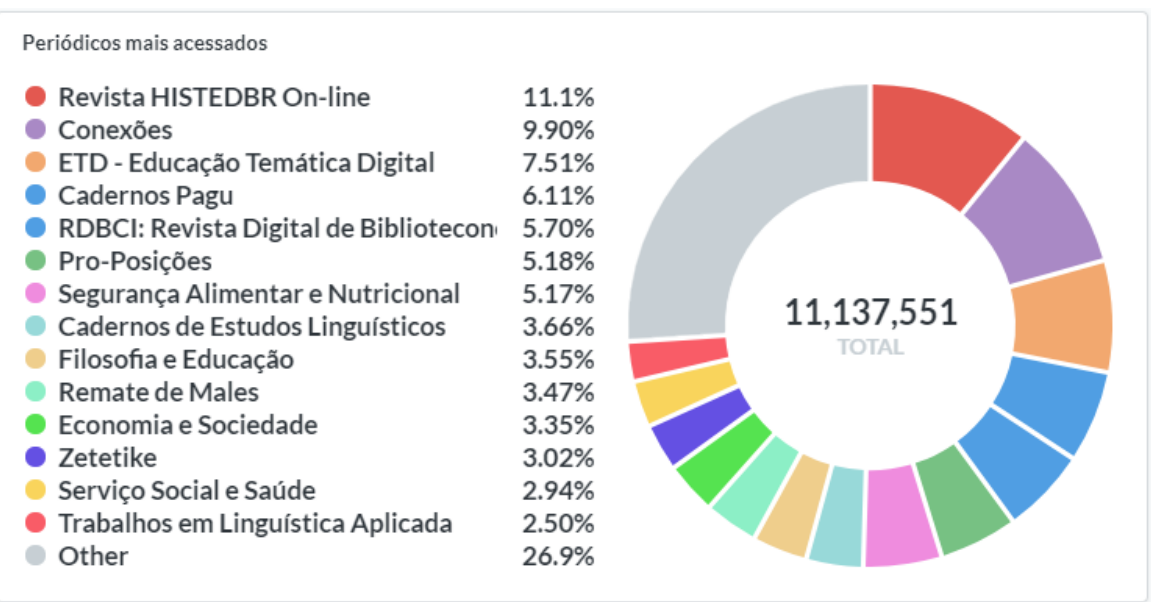

Figura 2 - Acessos aos periódicos no PPEC da Unicamp.

Fonte: PPEC (2021).

Ainda assim seguimos em projetos de divulgação, como na utilização das redes sociais. A equipe da revista está empenhada na divulgação da Conexões, @ revistaconexoes (Instagram); @rconexoes (Twitter e Facebook). A Conexões também pode ser acessada a partir da página principal da Faculdade de Educação Física.

Com o apoio do PPEC, modernizamos as ferramentas para administração do periódico, com a versão mais recente do Open Journal Systems, também implementamos a periodicidade de publicação contínua, com volumes anuais. Mantivemos a política de acesso aberto e ampliamos a equipe técnica com bolsistas custeados pela Unicamp. Muitas mudanças para que hoje publiquemos 45 artigos por ano, limite imposto pelo número de DOIs adquiridos pelo Sistema de Bibliotecas da Unicamp (SBU). Muitas mudanças para fecharmos o número de 2021 com um mês de antecedência. 
Em 2022, encerra-se a gestão desta editoria e temos a certeza de que entregamos um periódico consolidado na Educação Física brasileira. Se estas mudanças refletirem na estratificação do Qualis-Capes, muito bem, já que a revista avançou no último quadriênio de B5 para B3. Caso contrário, com os novos critérios baseados apenas em números de citações no Journal Citation Reports e nos seus fatores de impacto, se a revista não melhorar sua classificação, não será um desalento e continuaremos o trabalho pela reputação da revista independentemente de uma nota que tem como objetivo avaliar a pós-graduação brasileira e não a qualidade dos periódicos.

\section{REFERÊNCIAS}

A GAZETA. Nona Travessia de São Paulo a Nado. A Gazeta, São Paulo, mar. 1935.

PPEC - Portal de Periódicos Eletrônicos Científicos da Unicamp. Estatísticas do Portal. Campinas, Sistema de Bibliotecas da Unicamp, 2020. Disponível em:

http://stat.sbu.unicamp.br/public/dashboard/222f8922-3813-4776-bf6c-c55b0b32b744 Acesso em: 16 nov. 2021.

Artigo submetido ao sistema de similaridade Turnitin $®$.

A revista Conexões utiliza a Licença Internacional Creative Commons Atribuição 4.0, preservando assim, a integridade dos artigos em ambiente de acesso aberto.

A Revista Conexões é integrante do Portal de Periódicos Eletrônicos da Unicamp e associado/membro das seguintes instituições:

\section{A ABEC \&}

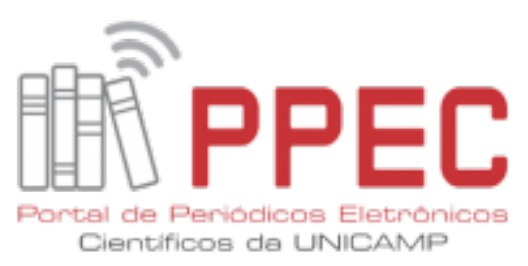

